\title{
A MORTE E A SOLIDÃO EM POEMAS DE DRUMMOND E BANDEIRA E A LITERATURA INFANTOJUVENIL
}

\author{
Juliana Lopes Melo Ferreira Sabino \\ Doutora em Linguística e Língua Portuguesa pela Pontifícia Universidade Católica de Minas \\ Gerais (PUC-MG) \\ julianalopes20@hotmail.com
}

\section{RESUMO}

O presente trabalho tem o objetivo analisar como se constrói as temáticas da morte e da solidão nos poemas de Carlos Drummond de Andrade e Manuel Bandeira, por meio das figuras de linguagem, tendo como corpus quatro poemas, dois de cada autor. Manuel Bandeira é um dos principais nomes da primeira geração do modernismo brasileiro. Dentre os poemas que compõem suas obras há vários voltados ao universo infantojuvenil, como "Trem de Ferro". No que se refere a Carlos Drummond, suas produções literárias não têm como público alvo as crianças, entretanto, grande parte de seus poemas são recomendados para leitura durante esta fase. Pretendemos evidenciar a literatura infantojuvenil como uma porta de entrada que conduz ao processo crítico e a níveis mais profundos de leitura. Um gênero que não consideramos menor, pois as diferentes habilidades e competências discursivas de leitura são desenvolvidas em cada fase de desenvolvimento do ser humano.

Palavras-chave: Carlos Drummond, Manuel Bandeira, morte, solidão.

\section{ABSTRACT}

The present work has the main objective of analyzing how the theme of death and solitude is constructed in the poems of Carlos Drummond de Andrade and Manuel Bandeira, through the use of the figures of language, using as corpus four poems, two of each author. Manuel Bandeira is one of the main names of the first generation of Brazilian modernism. Among the poems that make up his works there are several aimed at the universe of children and youth, such as the famous "Iron Train". Even though in the Drummonian literary productions the target audience is not especially directed at children, most of their poems are recommended for reading during this phase. Children's Literature should not be considered as a minor genre, but should be taken with the same importance as the others, because the discursive reading skills and abilities are developed in each stage of human development.

Keywords: Carlos Drummond, Manuel Bandeira, death, solitude. 


\section{Introdução}

O presente trabalho por objetivo analisar a maneira como é construída a temática da morte e da solidão nos poemas Os mortos de sobrecasaca e $O$ boi de Carlos Drummond de Andrade, presentes nos livros Sentimento do mundo (2004) e José (2012); e Consoada e Poema só para Jaime Ovalle de Manuel Bandeira, presentes nos livros Estrela da vida inteira (2008) e Seleta em prosa em verso (2007).

Sosa (1978) afirma que muito do que se escreve sob o rótulo "para crianças" é rejeitado pelo público infantil, talvez por serem os livros demasiadamente simplórios. Nesta esteira, perde-se a oportunidade de trabalhar a criticidade deste leitor, por pensar que apenas o adulto detém uma capacidade leitora, um letramento literário, cuja proficiência não cabe questionar, haja vista que as habilidades concernentes à prática de leitura não se restringem aos adultos. A tentativa deste estudo foi o de mostrar que há bons poemas, como os de nosso corpus, que poderão ser lidos tanto pela criança quanto pelo adulto. Estes exemplos de literatura podem atender ao público de diversas faixas etárias, embora nem toda a literatura é assim. Observe-se que há também a existência de literatura utilizada no Ensino de Jovens e Adultos (EJA), como mostra na pesquisa de Santos e Pinheiro (2017).

No que se trata ao projeto estético da literatura infantil, Silva (2006) pontua sobre o distanciamento entre um fazer poético de raiz mais tradicional e outra mais contemporânea. A primeira é rigorosamente restrita aos cânones, alicerçada no efeito de moral, e na segunda, impera, geralmente, um fazer literário, com licença à liberdade criativa e ao prazer estético, considerados pelo autor, peças propulsoras para um fazer poético. Uma das funções da literatura infantojuvenil é estimular a imaginação, 
subsidiando aos sujeitos sociais a oportunidade de se apropriarem de realidades lúdicas e repensarem a realidade que os cercam, além de atuar na formação do leitor.

Tentaremos encontrar uma conexão, destacando pontos semelhantes e divergentes relacionados aos temas supracitados, e para isso, além de explicitarmos as figuras de linguagem nos poemas, faremos uma comparação da utilização das mesmas nos poemas de cada autor, tentando compreender a maneira com que as temáticas são expostas nos poemas.

Candido (1996) pontua que o poeta, em seu ofício, efetua uma operação semântica peculiar, a de arranjar as palavras de maneira que o seu significado apresente ao auditor ou leitor um significado próprio ao conjunto do poema e que constitui o seu significado geral. Para este arranjo, são empregados recursos linguísticos como as figuras de linguagem que contribuem para uma maior expressividade da língua e, consequentemente, para a produção de efeito de sentido pretendido. Além das figuras de linguagem, existem diversos aspectos que podem ser analisados em um poema, e várias são as interpretações oriundas de uma análise que dependem do ponto de vista e conhecimento intelectual e social do leitor. Como pontua Candido, uma visão redutora da obra pode ser percebida quando há uma tentativa apenas de situá-la numa realidade social. Para Candido, "(...) o fator social é invocado para explicar a estrutura da obra e o seu teor de ideias, fornecendo elementos para determinar a sua validade e o seu efeito sobre nós" (CANDIDO, 1996, p. 25).

Para Conselho (2010), um texto poético consiste em um texto que expressa o sentimento e o mundo subjetivo do poeta e é apresentado em forma de versos que cantam a alma e os sentidos: “A poesia é o autêntico real absoluto, é sempre uma obra 
inédita, na medida em que o poeta ou artista, no momento da criação, experimenta o seu desabrochar" (CONSELHO, 2010, p. 18).

\section{A morte e a solidão - sentimentos abstratos e universais}

Consideramos que esses assuntos da morte e da solidão afligem, de forma intensa, a vida de muitas crianças e adolescentes. Em função do desamparo a muitas delas, por diversos motivos, é perceptível, por meio de suas falas e atitudes a dificuldade bem maior em lidar com essas questões, comparado aos adultos. A literatura permite tratar da solidão e da morte possivelmente, de forma mais branda e os poemas selecionados podem ser uma porta de entrada para isso.

A morte é um tema evocado constantemente na literatura, seja por seu significado enigmático ou pela tentativa em desvendar o seu mistério; vários escritores que utilizaram essa temática se basearam em experiências próprias ou de outrem. Existem tipos de morte tais como biológica, física, psíquica, espiritual e social, dentre outras, mas, neste trabalho, focaremos na morte natural, aquela que ocorre quando o organismo deixa de funcionar harmoniosamente.

A maioria das pessoas se recusa a discutir abertamente sobre a morte. Para o homem interessa o que se pode modificar, tocar e acrescentar, e o encanto da vida está em conseguir solucionar as questões mais complexas para então sair à procura de novas questões e com elas se entreter. É o ciclo vicioso da vida que se encaixa e se finaliza com a morte.

A morte é algo enigmático, complexo, pois não se planeja, e que segundo Bosi (2008) faz despertar reações diversas: 
Nesse universo de sentido, a morte suscita reações existenciais intensas e contraditórias: a angústia da finitude temporal ou a euforia da libertação; o temor do vácuo absoluto, de que a natureza é avessa, ou o êxtase que o arroubo místico inspira nas almas que anseiam desprenderse do cárcere do corpo (BOSI, 2008, p. 334).

Bosi ainda acrescenta que cada pessoa pressente e contempla a morte, sob diferentes ângulos que dependem das situações vivenciadas, mas que ao fim, terminam com o mesmo desfecho. A morte, que outrora era considerada importante pela sociedade, se torna um fato relegado ao esquecimento. Nesse sentido, Ferreira (2006) pontua:

Os comportamentos rituais vão sendo cada vez mais escassos, nomeadamente fechar as janelas, acender velas, aspergir água benta pela casa, afixar cartazes com a notícia do falecimento e solicitar serviços religiosos. Todos esperam que a pessoa enlutada seja capaz de exibir permanentemente um rosto sereno, que a sua expressão de dor seja comedida, de modo a demonstrar equilíbrio emocional (FERREIRA, 2006, p. 23).

Mencionar a morte nos dias atuais se tornou um ato que provoca uma tensão emotiva que não se adequa a regularidade da vida cotidiana. $\mathrm{O}$ homem procura ignorar a morte e desprezar tudo o que com ela se relacione, "com isso, a morte se tornou um tabu assumindo a forma de um mal-estar social e a sua redescoberta pode ser uma das vias de uma tomada de consciência" (FERREIRA, 2006, p. 25).

A morte é um tema que preocupa o ser humano e um dos meios mais eficazes e poderosos de representação, imitação ou até mesmo tentativas de explicação da morte é a literatura que a tem como um dos seus temas prediletos, associados a outros temas de significativas relevâncias, tais como o amor e a solidão. 
Sendo assim, a morte, com toda a sua complexidade e mistério, pode preencher a imaginação das crianças e jovens e suas mais diversas facetas podem ser encontradas na literatura, com histórias recheadas do mais puro terror a um simples verso que nos faz refletir sobre a vida e o destino que nos leva a todos, inevitavelmente, a participar de um último ato que é único e comum a todo ser humano.

A solidão é outro tema recorrente na literatura e para Pais (2013), ela se divide em duas margens: o isolamento e o relacionamento e, portanto, devemos nos desvincular dessa definição de que solidão significa estar só. Em relação à solidão, Pais (2013) considera que

a solidão não é o pouso inevitável de quem está só. Podemos estar sós sem que estejamos em solidão. E podemos viver um sentimento de solidão quando não estamos sós. É o que ocorre quando alguém, carente de relacionamentos, olha em seu redor e se vê entre estranhos ou indiferentes. A solidão diz respeito a um estado de subjetividade enquanto o 'estar só' se refere a uma situação visível e objetiva. 0 isolamento pode ser expressão da liberdade de cada um em querer estar só (PAIS, 2013, p. 2).

Para Octávio Paz (2006), o homem vive se adaptando, se camuflando, se escondendo para que não descubram sua vulnerabilidade. E nesse ato de se esconder, o homem cria um mundo próprio para si, dando lugar ao individualismo, vivendo em uma espécie de bolha que o isola de todo e qualquer tipo de interação com o outro.

A solidão, nos dias atuais, deixa de ser um sentimento próprio da alma para ser uma realidade do cotidiano moderno e, com a propagação das redes sociais, tudo se reverbera para uma solidão em massa. O contato e a interação já não são como antes, a convivência entre famílias já não se espelha em todos reunidos em uma mesa de jantar colocando as situações cotidianas em dia. A individualidade se tornou mais importante do 
que a interação e o convívio social e com isso, aumenta o distanciamento das pessoas, um isolamento que é considerado liberdade.

\section{A morte em Drummond no poema Os mortos de sobrecasaca}

A morte é uma temática constante na poesia de Carlos Drummond de Andrade e em uma pesquisa de natureza quantitativa, constata-se que quase um quarto dos poemas do autor tratam da morte. Drummond tematiza a morte utilizando imagens poéticas resultando assim em diferentes nuances.

No poema Os mortos de sobrecasaca o poeta estabelece com seus ancestrais falecidos, através da lembrança, uma forma de convívio e logo na primeira estrofe já nos deparamos com a menção da morte em um tom irônico:

\footnotetext{
Havia a um canto da sala um álbum de fotografias intoleráveis, alto de muitos metros e velho de infinitos minutos, em que todos se debruçavam na alegria de zombar dos mortos de sobrecasaca.
}

A primeira estrofe já se inicia com um verbo impessoal - havia - que traça o distanciamento do eu lírico com os mortos de sobrecasaca. Ele não compartilha do momento descrito na foto e apenas o observa com seu olhar irônico. As fotografias intoleráveis são a ponte que liga o passado ao presente e gera uma diversão naqueles que as contemplam e zombam deste passado.

No segundo verso podemos inferir que a construção da imagem do álbum "alto de muitos metros e velho de infinitos minutos" sugere a imagem de um túmulo que não 
guarda os corpos, mas sim a memória dos que se foram aprisionando ao passado. Ainda neste verso, a forma hiperbólica empregada pode ser uma porta de entrada para trabalhar a temática da morte com o público infantojuvenil, fazendo com que a dureza da morte se torne mais leve e, possivelmente, possa ser discutida até chegar a uma superação para aqueles que perderam alguém que estimam.

No terceiro e quarto versos "em que todos se debruçavam na alegria de zombar dos mortos de sobrecasaca", o eu lírico demonstra que existe uma dor da perda e que para suplantar essa dor é necessária a alegria de uma zombaria, recordando momentos felizes, e irrepetíveis, graças à morte, mas não apagados por ela e pelo tempo, e só a lembrança daria cor a vida novamente. Neste verso, a morte é trazida de maneira mais descontraída, alegre, que é um caminho estratégico para alcançar um efeito de sentido mais positivo para a discussão sobre a temática.

Já na segunda estrofe, o verme se torna uma metáfora para o tempo que tudo apodrece devorando as páginas do álbum, os retratos e inclusive a poeira. O primeiro verso nos mostra que a primeira coisa que perdemos ao morrer é a posição social. Quando a morte chega tudo isso desaparece. Ela equipara todo ser vivente e anula por completo a diferença de classes sociais, trazendo sempre dor, sofrimento, choro, e a imagem que se sobressai é única e universal: a do ataúde, o caixão fúnebre.

No segundo verso desta estrofe, o eu lírico demonstra que tudo após a morte é corroído, desde o material corporal até o pó de que somos feitos e a ele retornamos um dia. A única coisa que o verme não consegue roer é a memória. Já nos últimos versos temos a anadiplose com a repetição do verbo rebentava, recurso estilístico para enfatizar e expressar o soluço dos versos: 
Só não roeu o imortal soluço de vida que rebentava que rebentava daquelas páginas.

Vimos que o poema que começou de uma forma irônica nos dá um desfecho reflexivo, ao nos fazer pensar que a morte tudo pode devorar, mas o passado sempre dará os seus soluços que ecoarão no presente pela memória. Ademais, a memória é eternizada por meio das lembranças, ao passo que a morte é versificada por Drummond como uma passagem que tem dia e hora para acontecer, inclusive demonstrada por ações da natureza. Enfim, por meio da ironia, a morte é abordada como uma espécie de libertação, sublimando o "soluço de vida", que o eu lírico conjectura a vida e a morte, num ensejo de redescoberta, por meio de um mero álbum de fotografias de seus antepassados. Em suma, no poema Os mortos de sobrecasaca, o eu lírico tem um tom irônico, que zomba da morte e as figuras estilísticas utilizadas foram a hipérbole, a metáfora e anadiplose, tendo como foco principal para discorrer sobre a morte, o objeto fotografia.

Vale salientar que grande parte da produção destinada ao público infantojuvenil foi por muito tempo associada ao fazer pedagógico e instrucional, com um caráter meramente didático, afastados de uma essência estética. Posteriormente, mais precisamente, ao final do século XVIII, o rumo das histórias infantojuvenis é alterado por alguns escritores, que passaram a incluir o aspecto estético. Assim, consideramos que a partir da leitura do poema de Drummond, a realidade em torno da criança passa a ser (re) construída, quanto à sua simbologia e afetividade. O tempo é uma das temáticas mais usadas por Drummond. Neste poema, especialmente, a morte é versificada de uma maneira pessimista. A forma hiperbólica empregada no segundo verso associada à superação da dor por meio da 'alegria de uma zombaria', expressão típica do universo 
público infantojuvenil, permite à criança e ao jovem ver o seu universo sendo mimetizado lúdica e artisticamente.

Os versos fazem referência à maneira como o presente zomba do passado, e que pode até ser levado de forma descontraída para o universo infantojuvenil, entretanto, poderia aproveitar o ensejo para problematizar a questão, considerando a realidade de muitas crianças, adolescentes e jovens. Muitos destes vivem o momento 'agora' como único, sem pensar nas consequências futuras. Assim, a discussão em torno do existencialismo, do pessimismo associado ao tempo, a sensação de que a vida não faz muito sentido por ser passageira, é uma possível porta de entrada para adentrar no universo deste público. Pensar a efemeridade do tempo a partir do poema poderá subsidiar num debate escolar por exemplo. Neste momento, inquietações e angústias poderão ser sentidas ao colocar em discussão a temática do tempo, analisada como um verme que corrói tudo, arrancando de tudo o sentido. A esperança deverá ser apresentada a estes alunos, pois apesar de tudo há um soluço de vida que continua.

Tendo em vista que o público infantojuvenil se encontra ainda num processo de transformação em todos os aspectos, físico, psíquico, carácter, etc., o poema de Drummond poderá ser trabalhado também para discutir outras questões, como o respeito ao próximo, já que, durante essa fase, muitos não demonstram um olhar sensível ao outro, desprezando o que é diferente. Seria, talvez, importante mostrar, a partir da interpretação dos versos de Drummond que assim como hoje rimos do passado, das fotografias antigas, daquilo que consideramos antigo, o futuro irá rir de nós. Assim, a importância de se respeitarem às pessoas e suas culturas, pois amanhã, provavelmente, estaremos ultrapassados. Especificamente, o respeito à figura do idoso pode também ser explorada, haja vista que os mesmos estão sendo colocado à margem pela nossa 
sociedade. Acreditamos que estes debates fomentam maior introspeção dos alunos, fazendo-os refletir sobre o processo transformador do tempo, em que tudo num instante se transforma em passado.

\section{A morte em Bandeira no poema Consoada}

Manuel Bandeira também possui uma relação íntima com a temática da morte, pois conviveu com ela durante toda sua vida e o seu modo de expressá-la nos poemas reflete essa vivência. A tuberculose que sofria contribuiu na construção de sua poesia e ao perder a irmã e logo depois o pai, a preocupação com a morte passa a perturbar a existência do poeta que constrói parte de sua obra de uma maneira primorosa.

De acordo com Junqueira (2003), nenhum poeta teve uma convivência tão intensa com a morte quanto Manuel Bandeira. É claro que, nessas circunstâncias, não será difícil compreender a notável significação de que a reveste a morte na poesia bandeiriana (JUNQUEIRA, 2003, p. 274).

E toda essa experiência é demonstrada no poema Consoada, que possui uma estrofe com dez versos, sem rimas. A morte aqui é colocada de um modo subentendido, através da palavra "indesejada", criando-se um eufemismo, conferindo mais ênfase à mensagem, tornando-a mais expressiva. Considerando novamente o valor estético e não instrucional ou pedagógico como se trabalhava as literaturas infantojuvenis de antes, neste poema, é possível discutir a morte, "eufemizada" como a "indesejada das gentes", já que a mesma é tida como um tabu entre as pessoas, e, principalmente, o público mais jovem. Em sala de aula não há uma prática de explorar a temática da morte, mas o seu oposto é notadamente discutido. As pessoas se preparam para o nascimento de uma 
criança, para uma cerimônia religiosa, enfim, para vários momentos, entretanto, ninguém se prepara para a morte. Assim, o poema de Bandeira propicia reflexões sobre as possíveis reações diante de tal acontecimento. Por meio da exploração do eufemismo, acreditamos que a linguagem entre esse perfil de alunos poderá ser modalizada, ao menos, numa tentativa de procurar a suavização de algo que não se queira dizer ou que seja indesejável numa determinada situação de comunicação, já que, em muitos casos, o público infantojuvenil não tem o costume de refletir antes de emitir alguma declaração. É uma figura que poderá ser melhor explorada tanto no universo literário e se estendendo a outras situações linguareiras de comunicação.

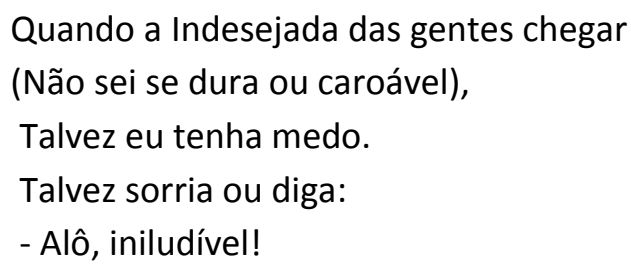

Ilustra-se aqui a relação que o eu lírico tem com a questão da finitude da vida, demonstrando temor, mas ao mesmo tempo proximidade, intimidade com a morte ao imaginá-la entrando em sua casa. Ao tratar a morte de uma maneira intimista, o poeta suaviza seu discurso ao se referir a uma visita que, na verdade, é indesejada. O presságio da morte também é um aspecto a se destacar e o presságio do eu-lírico difere da inquietação comum que se faz da morte. Ressalta-se também a repetição da palavra "talvez" que se configura em uma anáfora, enfatizando a incerteza do eu-lírico quanto aos sentimentos com a chegada da morte.

O fato do eu-lírico aguardar e até mesmo preparar o ambiente para a chegada da indesejada, demonstra o amadurecimento do poeta com relação a um tema complexo. 
Para Emanuel de Moraes, "a impressão que o poeta dá é a de haver transposto a barreira da vida. Sua intimidade com a morte atinge a um estágio excepcional. Aceita-a, sem desejá-la. Não há malquerenças" (MORAES, 2007, p. 243).

O título Consoada nos remete a uma ideia de preparação para um banquete e preparação para a morte, onde a protagonista é uma convidada indesejada. Prepara-se o ambiente para um embate previsível onde a iniludível sairá vencedora. Ou seja, a visita indesejada com funções e objetivos, já determinados, será recebida por um anfitrião que aceita e reconhece seu fim.

O meu dia foi bom, pode a noite descer.

(A noite com seus sortilégios.)

Encontrará lavrado o campo, a casa limpa,

A mesa posta,

Com cada coisa em seu lugar.

No primeiro verso da segunda estrofe, temos uma antítese com a utilização das palavras noite/dia. A palavra dia enfatiza a vida e o tempo vivido e a palavra noite o encontro com a morte. Na primeira estrofe o eu-lírico demonstra uma insegurança com relação à visita da morte nos versos "Talvez eu tenha medo / talvez sorria", que se transforma em uma certeza na segunda estrofe. A aceitação do eu-lírico com a chegada da morte é demonstrada no verso "Pode a noite descer", demonstrando assim o consentimento do eu-poético que demonstra saber exatamente o destino que o aguarda.

\section{A solidão em Drummond no poema $O$ boi}


Solidão é um sentimento universal que permite ao homem exteriorizar o seu eu, revelando uma parte oculta de si, e Drummond revela sua interioridade através de sua poesia, rompendo e expressando com palavras sua solidão interior e também a solidão do outro. Sua visão do mundo e do outro nasce do seu próprio eu. Nessa esteira, Mirna Dietrich (1987) considera que,

No encontro com o outro a busca de si. Busca incansável refletindo o mundo e nele deixando refletir. No ato de poemar o Eu-Outro, Drummond retrata a solidão e rompe o isolamento individual de homem-poeta fazendo sua projeção interna existencial. A partir de seu mundo apreende o sentido de ser do outro (DIETRICH, 1987, p. 13).

A solidão pode ser uma escolha ou pode ser imposta por alguma situação. Quando vivida conscientemente, ela pode ser renovadora levando a uma superação do ser. Os poemas de Drummond explanam a solidão que atinge o homem, que ao nascer se destina ao encontro e ao mesmo tempo à solidão e, para isso, o poeta recorre semanticamente às palavras com esse viés como "só", "sozinho", "ilha", "solidão", "ermo", "isolado", "deserto", demonstrando, assim, a experiência da existência humana.

Drummond utiliza uma contínua indagação sobre a vida e a inserção desta no ser humano, expressando a complexidade do mundo na solidão interior do homem. Sua poesia indaga o homem com suas inquietações, suas angústias e sua solidão, ocasionados pela pressão da sociedade no indivíduo, pela falta de tempo, pelas atribulações da vida que fazem com que o homem se esquive de conviver, de interagir com os outros. Para Dietrich (1987, p. 33) "nos versos de Drummond subjazem inquietações com o homem que, em seu hermetismo, não rompe o isolamento que o cerca e, por isso, fica cada vez mais só". 
A poesia Drummondiana segundo Dietrich (1987), se caracteriza por um estilo poético filosófico demonstrado no que se pretende dizer, "por meio dela vai se aprofundando a sua capacidade de expressar o seu pensar e poetar sobre o homem e seu Ser, pois são eles um poema a começar". E ainda completa:

Os poemas de Drummond são uma válvula de escape para o poeta que um gauche na vida - tem em sua obra de arte uma forma de exteriorizar o que viu no "vasto mundo" ao seu redor: solidão (DIETRICH, 1987, p. 33).

No poema $O$ boi, Drummond utiliza a imagem da cidade grande com todos os seus sons e movimentos para explanar a solidão do homem que mesmo em um espaço imenso, rodeado por várias pessoas, está só como um só boi no pasto. O poema é composto por quatro estrofes, três quartetos e uma sextilha, com rimas interpoladas. $\mathrm{Na}$ primeira estrofe o eu lírico destaca a solidão do homem em meio aos sons e aos movimentos típicos da cidade grande comparando-o com o boi sozinho no campo, ou seja, mesmo em meio ao movimento fervilhante da cidade, o homem está só:

\footnotetext{
Ó solidão do boi no campo, ó solidão do homem na rua! Entre carros, trens, telefones, entre gritos, o ermo profundo.
}

As figuras de linguagem encontradas nesse poema são a anáfora, a prosopopeia, a metáfora e o paradoxo. A anáfora é observada a partir da repetição da expressão "Ó solidão", marcando fisicamente o processo de ênfase da solidão vivida. Neste aspecto, considerando as lutas internas com que muitos alunos vêm enfrentando, com consequências até fatais, faz-se importante a discussão sobre a temática da solidão, em 
níveis profundos, entre um público que está ainda num processo de transformação. Ao se discutir sobre a anáfora supracitada, talvez ganhe relevo um grito de socorro despercebido pela figura do professor e também por parte dos alunos de alguém que precisa ser ajudado e que a partir daí possa alcançar esse desejo que estava escondido. Essas e outras práticas poderão ser realizadas considerando os aspectos emocionais presentes em todas as situações de ensino-aprendizagem, que segundo Fleck (2008) "vão desde a motivação, interesses, gostos, preferências, afinidades, a distúrbios, traumas, dificuldades e complexos. Fechar os olhos para esta realidade é conduzir o processo por veredas utópicas que resultarão apenas nos comentários triviais de que nossos alunos não leem, não se empenham, não têm condições de aprendizagem favoráveis, entre tantos outros". (FLECK, 2008, p. 18). Assim, há barreiras emocionais que por meio da leitura podem ser quebradas; e outras que devem ser traçadas por outros caminhos. A metáfora associada à prosopopeia vem contribuir para a força de expressão do paradoxo, que ganha ares de um pensamento aparentemente contrário: a solidão em meio aos ruídos da rua.

O eu lírico demonstra neste poema que para estar só não é necessário estar isolado e que a cidade e seus movimentos constantes e intermináveis se comparam ao ermo, ao deserto interior de cada indivíduo. O progresso da cidade aumenta a desumanização e consequentemente anula os sentimentos e os sonhos do homem. No poema $O$ boi, a solidão é explanada em um ambiente cercado por sons e movimentos enfatizando a ideia de que mesmo acompanhado por pessoas de todos os lados, o eu lírico está só e utiliza a imagem de um boi no campo para explicar essa solidão. A cidade, com sua tecnologia, com sua movimentação constante, não apazigua a solidão do eu lírico, que em meio a tantos movimentos se torna cada vez mais solitário. Ademais, o 
DOI: 10.12957/palimpsesto.2019.40180

ambiente é um espaço aberto, a cidade com toda sua movimentação rotineira e seus sons habituais, composta por casas, carros, homens e objetos variados.

\section{A solidão em Bandeira no Poema só para jaime ovalle}

Em Poema só para Jaime Ovalle de Bandeira temos também a solidão como temática central, demonstrada pela reflexão do eu lírico em sua vida passada, revivendo e repensando os momentos vividos. A poesia tem versos livres, com uma única estrofe com nove versos disformes, ou seja, nenhum verso tem a mesma métrica do outro. A primeira imagem que focalizamos com o início do poema é a de um quarto, um espaço fechado e escuro:

Quando hoje acordei, ainda fazia escuro.

A segunda imagem que temos é a do espaço aberto que é definido pela chuva e reforça o ambiente vazio, escuro e solitário, o ambiente exterior se reflete no ambiente interior:

Chovia.

Chovia uma triste chuva de resignação

Temos aqui uma figura de construção que é o paralelismo com a repetição da palavra chovia e também uma personificação, pois a chuva ganha uma característica tipicamente humana. A personificação é um recurso bastante empregado em fábulas, gênero muito explorado durante a fase infantil, assim, haveria um continuum, ou seja, a 
manutenção da figura de linguagem já trabalhada antes da fase juvenil e que poderia ser potencializada a partir do sentido pretendido no poema.

No verso "Como contraste e consolo ao calor tempestuoso da noite", temos uma aliteração com a repetição de sons das palavras contraste/consolo e um paradoxo com as palavras calor/tempestuoso, em que a oposição se funde, produzindo efeito de sentido de contradição que permeia o âmbito das ideias.

Os verbos "acordei, levantei, preparei, deitei, acendi, fiquei, amei" demonstram que o eu lírico pode ser o próprio autor que dialoga com seu grande amigo e compositor Jaime Ovalle e a quem dedica o poema.

Neste poema constata-se a solidão do eu lírico ao recordar o seu passado, sua vida e as mulheres que amou. Nota-se que foram mulheres e não apenas uma mulher. E, apesar de ter amado várias, agora ele tem a companhia apenas das lembranças do passado, revivendo solitário em seu quarto os bons momentos.

No Poema só para Jaime Ovalle, o ambiente é o quarto escuro e solitário e o eu lírico é acompanhado apenas de seus pensamentos sobre os amores do passado. A solidão do eu lírico é imposta pelos momentos que se foram e pela demonstração de humilde aceitação que o faz se acomodar, ao recordar algo que um dia foi notório em sua vida. Ademais, o quarto é um ambiente restrito e a única movimentação que se tem é a do eu lírico, acompanhado de seus pensamentos reflexivos.

Pesquisas já revelam que o isolamento do público infantojuvenil em seus quartos indica a vitimização de um sistema educacional, com até perseguição por causa dos seus baixos resultados e a partir daí passam a enxergar os seus pares com desconfiança e receio. A ausência de estratégias e medidas por parte do sistema educacional atrelada à deficiente comunicação entre os pais e os filhos de certas famílias faz com que o 
problema do isolamento e, consequente, solidão se agrave. A partir do lugar físico interno assinalado no poema, o quarto, podemos propor uma análise coletiva junto a este público, pois, infelizmente, muitos permanecem confinados em um quarto numa repleta solidão, podendo se transformar, a depender da gravidade, num isolamento patológico. 0 próprio poema, composto por uma única estrofe já marca fisicamente a solidão vivida. Assim, acreditamos que a tentativa de exteriorizar as aflições internas acerca do eu-lírico poderia suscitar questões conflituosas entre os próprios alunos, despertando uma das funções da literatura, o fazer- sentir.

\section{Considerações finais}

Foi possível observarmos no lirismo de ambos os poetas elementos semelhantes e variantes no que se refere à presença da morte e da solidão, e que destacamos ao longo de nossa análise. Tentamos mostrar algumas formas práticas das temáticas a serem debatidas em sala. As temáticas manifestaram-se como símbolos das incertezas da humanidade e nos colocaram a pensar nos limites da vida envolvendo-nos na complexidade da existência.

Consideramos a relevância de se trabalhar não apenas na fase adulta poemas que explorem um repertório linguístico variado, ampliando a capacidade de expressão nas diferentes situações de comunicação enfrentadas diariamente. As propostas elucidadas para se trabalhar as duas temáticas de Bandeira e Drummond nos faz pensar nas reflexões tecidas por Lajolo (1994, p. 106), quando postula que a literatura assume um papel de extrema importância, pois por meio dela os diferentes imaginários são ampliados, assim também em relação às diferentes sensibilidades, valores e 
comportamentos, por meio dos quais uma sociedade exprime e debate, simbolicamente, seus embaraços, seus anseios, suas fantasias, num ensejo de solução como ora tentamos explorar.

Por fim, conforme Fleck (2008, p. 25): “compreender a importância da iniciação do sujeito no mundo literário, por meio da exploração da literatura infantil e infanto-juvenil (sic), é lançar boas sementes num solo fértil, que, no futuro, revelará frutos como a criticidade, o engajamento social e político, a consciência de que todo ser humano é agente histórico".

\section{Referências}

ANDRADE, Carlos Drummond. Sentimento do mundo. 4. ed. Rio de Janeiro: Record, 2004. José. Posfácio Júlio Castañon Guimarães. São Paulo: Companhia das Letras, 2012.

BANDEIRA, Manuel. Estrela da vida inteira. Rio de Janeiro: José Olympio Editora, 1987.

BOSI, Alfredo. Meditatio Mortis. A poesia de Juan Reventós. In: Estudos Avançados, São Paulo: Instituto de Estudos Avançados da Universidade de São Paulo, v. 22, n. 63, p. 334336, 2008.

CANDIDO, Antônio. O estudo analítico do poema. 3. ed. São Paulo: Humanitas, 1996.

CONSELHO, A. C. P. M. A poesia de Carlos Drummond de Andrade em manuais escolares do ensino médio no Brasil. Dissertação (Mestrado em Literatura de Língua Portuguesa) Faculdade de Letras, Universidade de Coimbra, 2010.

DIETRICH, Mirna. Drummond: o homem-poeta e a solidão. Letras de Hoje, Porto Alegre, PUCRS, v. 22, n. 3, p. 13-34, set. 1987.

FERREIRA, Isabel Maria da Cunha. A morte em quatro narrativas brasileiras da segunda metade do século XX. 2006. 179f. Dissertação (Mestrado em Literaturas Românicas) Faculdade de Letras da Universidade do Porto, Porto Portugal, 2006. 
FLECK, G. F. O papel da literatura Infantil e Infanto Juvenil na formação do leitor. Revista Língua \& Literatura, Universidade Regional Integrada ao Alto Uruguai e da Missões, p. 1128, 2008.

JUNQUEIRA, Ivan. (org.). Testamento de Pasárgada: antologia poética - Manuel Bandeira. 2. ed. Rio de Janeiro: Nova Fronteira, 2003.

LAJOLO, M. Do mundo de leitura para a leitura do mundo. 2. ed. São Paulo: Ática, 1994. MORAES, E. Seleta em prosa e verso. Rio de Janeiro: José Olímpio, 2007.

PAIS, José Machado. Sobre Cultura. Tempos de solidão. Suplemento da Revista Ciência Hoje, Belo Horizonte, n. 14, p. 2-3, dez. 2013.

SANTOS, I. C. A. T dos; PINHEIRO, A. S. A literatura infanto juvenil no ensino de jovens e adultos em Dourados-MS: a difícil tarefa de formar leitores. Leitura: Teoria \& Prática, Campinas, São Paulo, v.35, n.70, p. 117-131, 2017.

SILVA, M. Poesia infantil contemporânea: dimensão linguística e imaginário infantil. Imaginário v. 12, n. 13 São Paulo dez. 2006.

SOSA, Jesualdo. A literatura infantil. Tradução James Amada. São Paulo: Cultrix, Ed. da Universidade de São Paulo, 1978.

Recebido em 15 de fevereiro de 2019. Aceite em 4 de abril de 2019. 